\begin{tabular}{|c|l|}
\hline Title & Role of ozone in the solar cycle modulation of the North A tlantic Oscillation \\
\hline Author(s) & Kuroda, Y uhiji; Yamazaki, Koji; Shibata, Kiyotaka \\
\hline Citation & Journal of Geophysical Research, 113(d14), D14122 \\
\hline https:/doi.org/10.1029/2007JD009336 \\
\hline Issue Date & 2008 07-26 \\
\hline Doc URL & http://hdl.handle.net/2115/34478 \\
\hline Rights & An edited version of this paper was published by A GU. Copyright 2008 A merican Geophysical Union. \\
\hline Type & article (author version) \\
\hline File Information & KurodaY Yamazaki-Shibata JGR.pdf \\
\hline
\end{tabular}

Instructions for use 


\title{
Role of ozone in the solar cycle modulation of the
}

\section{North Atlantic Oscillation}

By Yuhji Kuroda ${ }^{1}$, Koji Yamazaki $^{2}$ and Kiyotaka Shibata ${ }^{1}$

${ }^{2}$ Faculty of Environmental Earth Science, Hokkaido University, Sapporo, Japan

\begin{abstract}
The effect of ozone on the 11-year solar cycle modulation of the winter-mean North

10 Atlantic Oscillation (NAO) is examined through analyses of observed meteorological and ozone data from 1978 to 2000. It is found that a significant ozone anomaly associated with the winter NAO is created in winter in high solar (HS) years only and the anomaly persists from spring to summer, creating a large temperature anomaly in the lower stratosphere through radiative heating. Such a temperature anomaly in the 15 stratosphere creates anomalous temperature of opposite sign at lower heights and anomalous zonal wind in the polar area of the troposphere in summer. The associated surface signal is very similar to the summer Arctic Oscillation (Summer-AO). The mechanism for the formation of the Summer-AO is also discussed.
\end{abstract}




\section{Introduction}

As solar radiation is almost the only energetic input on the climate system, it has been believed for a long time that the solar variation has a large impact on the climate [e.g., Haigh, 2003; Pap and Fox, 2004]. In fact, analysis of recent observations shows

25 that the variation of solar flux associated with the 11-year cycle is as much as several tenths of a percent for shorter ultra-violet wavelengths [Rottman, 1988; Lean et al., 1997] and an associated significant temperature change was found in the upper stratosphere [Hood et al., 1993; McCormack and Hood, 1996].

Recent observations also indicate that tropospheric climate "modes" related to the stratosphere show significant structural modulation with the 11-year solar cycle. Kodera [2002, 2003] and Ogi et al. [2003] found that the winter mean North Atlantic Oscillation (NAO) shows significant modulation associated with the solar cycle. They found that variability of the sea level pressure (SLP) associated with the winter-mean

NAO becomes hemispheric as for the "Arctic Oscillation" (AO) [Thompson and Wallace, 1998] and it extends to the upper stratosphere and persists until the following 
summer in high solar (HS) years, whereas it is a tropospheric local variability and has less persistence in the low solar (LS) years. Further, Kuroda and Kodera [2005] found the late-winter mean Southern Annular Mode (SAM) shows a similar solar cycle modulation as the winter NAO. They also suggest that the longer persistence of SAM in HS years originates from the ozone anomaly in the lower stratosphere, which is created by the modulation of Brewer-Dobson circulation in late winter. Such a modulation of SAM was also well simulated by a chemistry-climate model [Kuroda and Shibata, 2006].

Concerning the persistence of the winter NAO signal into the summer in HS years, Ogi et al. [2003] suggested that surface conditions such as snow, sea ice, and sea surface temperature (SST) maintain a memory of the winter NAO. This surface-memory scenario is in contrast to the ozone-memory scenario [Kuroda and Kodera, 2005]. The

50 purpose of the present study is to examine whether ozone in the stratosphere becomes a source of the structural modulation of the winter NAO as it is for the SAM in the southern hemisphere. 


\section{Data and analysis method}

The meteorological data we used in this study are from the 40 -year reanalysis data of the European Centre of Medium-range Weather Forecasts (ERA40) [Uppala et al, 2005]. We used 23 years of data from 1978 to 2000. In all analyses monthly-mean data have been used. Quantities containing second order effects such as the E-P flux or velocities above 100-hPa are estimated by solving the transformed Eulerian mean equation with zero vertical residual velocity at $0.5 \mathrm{hPa}$, as in Kuroda and Kodera [2001], and they are combined with those calculated directly from analyzed winds and eddies at the 100-hPa level and below.

The ozone data we used is the monthly data that described in Randel and $\mathrm{Wu}$ [2007]. This has been combined from two satellite data of Stratospheric Aerosol and Gas Experiment (SAGE) I and II [e.g., Wang et al., 2002] and ozonesonde data at the polar region. As these satellite observations cover latitude only from about $55^{\circ} \mathrm{S}-55^{\circ} \mathrm{N}$, ozonesonde data up to $30-\mathrm{hPa}$ and extrapolation of the satellite data is made poleward of $60^{\circ}$ latitude. Continuous data is then made by multi-regression method including the decadal trend, solar cycle, and Quasi-Biennial Oscillation (QBO) from gappy data. See 
Randel and $\mathrm{Wu}$ [2007] for more detail. As the data covers from 1979 to 2005, and the data in December 1978 is absent, we made this from 5-year average of December data from 1979 to 1983.

From meteorological and ozone data, we calculated also the solar heating rate with the radiation code used in the chemistry-climate model of the Meteorological Research Institute [Shibata et al, 2005]. Changes in the ultra-violet (UV) irradiance 80 were adopted from data obtained by Lean et al. [2001]. The NAO index used in the present study is the same as that used in Kodera [2002, 2003] and Ogi et al. [2003]. It is the difference in the normalized monthly mean SLP between Lisbon and Stykkisholmur as calculated in Hurrell [1996]. In this study, we used a winter-mean NAO index as the average from December to February (DJF). The time series of the winter-mean NAO 85 index, together with the solar-cycle index, is presented in Figure 1.

First we classified each year as either HS or LS according to the December-toMarch (DJFM) mean $10.7 \mathrm{~cm}$ solar radio flux: If the flux of a year is higher (lower) than the average, the year is categorized as a HS (LS) year. In this way, 10 (12) winters 90 were selected as HS (LS) years (see lower panel of Figure 1). Correlation analysis was 
then performed for the HS and LS years separately, based on DJF mean NAO indices in a method similar to that used by Kodera [2002, 2003] and Ogi et al. [2003].

Though ERA40 data is available from the surface to $1 \mathrm{hPa}$, we have restricted 95 our analysis to the more reliable region from the surface to $10-\mathrm{hPa}$.

Most of the figures in this paper present correlation or regression with the DJF mean NAO index. This means that the figures are relative to a positive change in the DJF mean NAO index.

\section{Results}

Before performing the correlation analysis, it will be useful to examine climatologies. To this end, we examined the climatologies of basic quantities for the HS

105 and LS years and their differences. Figure 2 presents the climatologies of two-month mean zonal wind from December-January (DJ) to June-July (JJ) for HS and LS years and their differences. It can be seen that climatological zonal winds are very similar for HS and LS years. However, there are significant differences between them; the 
meridional dipole structure of anomalous zonal wind in the stratosphere is prominent in

110 DJ, as well as the polar tropospheric wind in AM. Winter signals indicate prominent poleward and downward movement of anomalous zonal wind with time if monthly data is used (not shown). The signal in DJ captures this. Such a signal should be closely related to the solar signal [Kuroda and Kodera, 2002; Kodera and Kuroda, 2002]. The variability of the zonal wind is a little larger in the LS than HS years in the stratosphere

115 throughout the period. It is noted that the difference of zonal wind in JJ is quite small in the troposphere, but the variability is large in the high-latitude troposphere both in HS and LS years.

Figure 3 indicates the same plot except for ozone densities. It can be seen that

120 ozone densities tend to become greater with increasing altitude. The densities also become greater with increasing latitude in the lower stratosphere but with decreasing latitude in the middle stratosphere. The variability is generally higher in winter and decreases from spring to summer. Though the climatological values of ozone densities are very similar between HS and LS years, there are significant differences between

125 them, as depicted in the lower panels. In fact, ozone density in HS years tends to be about $2-4 \%$ greater in the stratosphere throughout the period [Soukharev and Hood, 
2006]. It is noteworthy that the difference between the climatology of the HS and LS years is a little greater than the standard deviation of each year. mean NAO index, calculated separately for “all”, HS, and LS years. Calculations are performed for two-month means from DJ to JJ. Here, correlation greater than 0.6 is contoured in steps of 0.1 and regions of correlation greater than 0.5 are shaded. As the 95\% level of statistical significance corresponds to a correlation of $0.63(0.57)$ for the sample size of HS (LS) years, the area of correlation greater than 0.6 corresponds to about the $95 \%$ significance level. Correlation of 0.5 corresponds to approximately the $90 \%$ level of significance. As the correlations of 0.5 and 0.6 correspond to much higher levels of significance for the case of "all years," the same plot is compared with both HS and LS years.

In the correlation for “all years”, a prominent signal appears in DJ but not afterward. In DJ, a meridional dipole signal centered at $55^{\circ} \mathrm{N}$ and $35^{\circ} \mathrm{N}$ appears in the troposphere. Although the low-latitude signal is confined to the lower troposphere, high-latitude signal extends to about the 50-hPa level. 
The situation was quite different when we performed the same analysis but stratified according to the solar cycle. In HS years, the larger area of significant correlation extends further into the upper stratosphere in DJ and after diminishing in the following months the signal appears again in JJ with the same polarity. Note that the positive correlations poleward of $50^{\circ} \mathrm{N}$ in $\mathrm{JJ}$ mean that a positive $\mathrm{NAO}$ in winter is associated with a stronger westerly vortex in the following summer. LS years, however, show neither the extension to the stratosphere in DJ nor reappearance in JJ.

To examine the source of difference between the HS and LS years, we compared

155 the winter NAO signals from December to April when the differences in the signals are more apparent. Figure 5 compares the E-P flux and its divergence ( $1^{\text {st }}$ and $3^{\text {rd }}$ rows), and ozone density and residual velocity ( $2^{\text {nd }}$ and $4^{\text {th }}$ rows) in HS (upper panels) and LS years (lower panels). It can be seen that a large negative correlation of ozone is developing in middle-latitude middle stratosphere to high-latitude lower stratosphere in January only 160 in HS years. This means that a positive NAO index in winter is associated with a negative ozone anomaly in HS years. The formation of large correlation of ozone in HS years corresponds to the weakening of the Brewer-Dobson circulation, shown by 
equatorward arrows around $30-40^{\circ} \mathrm{N}$ and $30-\mathrm{hPa}$ in both December and January, and upward arrows around $70^{\circ} \mathrm{N}$ and $200-30 \mathrm{hPa}$ in January. Such anomalous residual

165 circulation should be driven by the positive anomaly of the E-P flux divergence above these levels, which is more clearly formed in HS years than LS years. Such differences in the E-P flux divergence should originate from differences in the E-P flux and therefore their existence implies reduced upward wave propagation in the extratropical stratosphere in HS years compared to LS years in January.

The extension of correlation of ozone in April in HS years also corresponds very well with a weakening of the Brewer-Dobson circulation, shown by upward and equatorward arrows around $70-80^{\circ} \mathrm{N}$ and $200-30 \mathrm{hPa}$, which will be driven by a positive E-P flux divergence at the stratosphere.

Such a correlation of ozone persists through spring to summer in HS years, whereas it is thoroughly absent in LS years. It should be noted as well that an apparent temperature signal also persists from spring to summer in HS years, but it is not present in LS years (not shown). 
To see how a summer AO-like signal evolves with time in HS years, we compared regressed zonal-wind, temperature, ozone density, and solar heating from May to August (Figure 6). Corresponding to a large negative anomaly of ozone, the solar heating is significantly reduced in the stratosphere in May. Such solar heating 185 corresponds well with anomalous temperatures in the stratosphere, although the area of significant correlation is small due to larger variability. This colder temperature signal in the stratosphere becomes more significant and persistent in June. In particular a vertical dipole structure of anomalous temperature, one in the stratosphere and the other in the troposphere, centered around $65^{\circ} \mathrm{N}$ is prominent. This dipole structure persists until August with slow equatorward propagation. The center of higher temperature in the troposphere is accompanied by an area of Eulerian downward flow. This is associated with anomalous Eulerian mechanical forcing centered around 300-hPa and $70^{\circ} \mathrm{N}$ (not shown). Anomalous zonal wind centered around $300-\mathrm{hPa}$ and $75^{\circ} \mathrm{N}$ in June corresponds well with the anomalous higher temperature in the troposphere through the 195 thermal wind relationship. Wave forcing around the tropopause is created through the modification of wave propagation by anomalous zonal wind that extends to the stratosphere. Thus wave forcing around the tropopause, the vertical dipole structure of 
the temperature, and the zonal wind in the polar area are sustained by positive feedback in summer.

Figure 7 illustrates the horizontal structure of the regressed temperature in the lower troposphere and stratosphere from June to August. It can be seen that associated with the vertical dipole signal of the temperature seen in Figure 6, warmer areas in the lower troposphere exist just below the cooler areas in the lower stratosphere. It is also noteworthy that the horizontal pattern shows almost zonal wavenumber 3 structure. These clearly suggest existence of strong linkage between the stratosphere and troposphere in this period.

The surface signal in the polar region in the summer of HS years is very similar

210 to the Summer Arctic Oscillation (Summer-AO) or Summer Northern Annular Mode proposed by Ogi et al. [2004]. Such AO-like structures will be created by the wave driven meridional circulation in a similar manner to the winter AO [Kuroda, 2005, 2007a]. Therefore we compared zonal-mean SLP ( $1^{\text {st }}$ and $3^{\text {rd }}$ rows $)$ and potential surface pressure change (PPC) $\left(2^{\text {nd }}\right.$ and $4^{\text {th }}$ rows $)$ caused by regressed wave forcings associated 215 with the winter-mean NAO in HS years (upper panels) and these with Summer-AO 
(lower panels) in Figure 8. PPC is defined as a surface pressure change if frictional and diabatic effects are absent, and it is evaluated by the zonal-mean quasi-geostrophic model on a sphere as used in Kuroda [2005]. See Appendix A for the detail of the model. (forcing due to eddy momentum flux) at $500-\mathrm{hPa}$ and above. As can be seen from the comparison of the SLP and PPC, they are roughly proportional to each other for both the Summer-AO and the signal for the winter-mean NAO, although the signal with winter-mean NAO in June is slightly modified due to larger downward flow around $65^{\circ} \mathrm{N}$ as previously described. It takes about eight days to produce the SLP anomaly with PPS alone, which is closely related to the frictional damping effect on the meridional circulation at the surface. The similarity of the red line to the circle one means that the SLP signal associated with the winter-mean NAO in HS years is created mainly by the meridional circulation driven by the mechanical forcing in the upper 230 troposphere as is the case for the Summer-AO. Note that the vertical axes of the upper panels are just half of the lower panels. Thus the amplitude of the SLP associated with the winter-NAO in HS years is about half size of the typical Summer-AO in summer. 
This is because that the effect of the winter-NAO through ozone is only one source to create the Summer-AO.

\section{Discussion and remarks}

The analysis presented here suggests that the reappearance of the winter-NAOindex signal in summer in HS years originates from the formation of ozone anomaly in the lower stratosphere in winter. Since the winter ozone anomaly in the mid-latitude

240 lower stratosphere persists until the following autumn [Fioletov and Shepherd, 2003], the ozone anomaly associated with the NAO in HS years becomes a persistent heat source and creates anomalous temperatures in the stratosphere in summer. This is the same as that occurs in the SAM [Kuroda and Kodera, 2005]. However, the SAM signal gradually disappears with the seasonal evolution in summer whereas the AO-like signal

245 disappears quickly in spring but it reappears in summer for the NAO. So the key question we should resolve is why ozone anomaly does not work in spring but works well only in summer in HS years.

As had been seen in Figure 6, formation of Summer-AO signal appears firstly in 250 June, but it is not very clear how the signal firstly appears in June. So we had analyzed 
this period by 10-day mean data. Upper panels in Figure 9 show the regression of the Eulerian mechanical forcing with a Eulerian meridional circulation, whereas lower panels show the zonal-mean temperature with a residual circulation. The result shows that the higher temperature anomaly in the troposphere is created firstly in mid-June, 255 associated with the downward Eulerian flow around $65{ }^{\circ} \mathrm{N}$. The flow starts from the first 10-day of June, though it is weak, and corresponds well with anomalous mechanical forcing at the upper troposphere. The area of downward Eulerian flow exists just north of the downward residual flow in mid-June. It is interesting to note that the tropospheric downward flow seems to be connected with the stratospheric colder air if 260 we look closely the residual velocity in the stratosphere for the second to third 10-day. This will explain why warmer areas exist just below the colder areas in Figure 7. In fact, if heavier cooler air is nearly vertically transported to the troposphere, it will create warmer zone in the troposphere. This can occur in June because climatologically the temperature gradient between the lower stratosphere and the upper troposphere becomes 265 smaller and less stable as it evolves with time during this season (Figure 10). It is interesting to compare that though the stratification near the mid-latitude tropopause in the $\mathrm{NH}$ is less stable in summer, it is most stable in the SH. So formation of vertical 
flow from the stratosphere in summer seems to be a key process, although this should be examined in more detail in a future study.

We had evaluated the PPC by using climatological stability of each month in Figure 8. We had examined the effect of these stabilities on the PPC by changing the stability to that from winter-mean value. The result indicates that the PPC at the pole becomes about $10 \%$ smaller if winter-mean values are used. It indicates that the low stability in summer enables wave forcing in the upper troposphere to easily change the lower tropospheric climate.

The ozone data we had analyzed in the present study was made by multiregression method including the decadal trend, solar cycle, and Quasi-Biennial 280 Oscillation (QBO) [Randel and $\mathrm{Wu}, 2007$ ]. So using the data for the solar cycle problem as the present study may have problem because the data is made by using solar cycle itself. To verify whether large ozone signal in HS years is not special for the present data, we also performed the same analysis by another data. The other ozone data we used has been combined from two different datasets. One is the version 8 Solar 285 Backscattered Ultraviolet (SBUV) data [Frith and Stolarski, 2005], which contains the 
monthly zonal mean mixing ratio at stratospheric pressure levels of $50-$ to $0.5-\mathrm{hPa}$, as well as the column ozone between pressure levels, from November 1978 to 2003. The other is the original SAGE II data from October 1984 to 2000 [e.g., Wang et al., 2002]. By merging these two datasets, we produced a combined data set extending from 290 November 1978 to 2000, in which SBUV(/2) is used in the stratosphere at 50-hPa level and above, and SAGE II is used below. As the SAGE II data start from October 1984, lower level data before that date was obtained from seasonally varying climatological profiles of SAGE II data, scaled to be equal to the lowest column ozone from the surface to the 64-hPa level in SBUV(/2) data. All missing data except for the polar area 295 were replaced with values obtained by interpolating in time even just after the Pinatubo eruption. The same result as Figure 6 except for using this ozone data is shown in Figure 11. Signal for the LS years was found to be very weak (not shown). It is found that the signal is not so strong as that obtained in the present study but it is still present. It is interesting to note that the signal is very similar to the signal of temperature. Ozone 300 signal is still present only in HS years in the alternative dataset.

The large correlation of ozone generated by modulation of the Brewer-Dobson circulation in winter was the key process to convey the winter-NAO signal to summer 
in HS years. This can be traced back to the fact that the stratospheric wave propagation

305 was more strongly correlated to the winter-NAO index in HS years (Figure 5). One possible source of this stronger correlation in HS years is that it originates from larger amplification of the planetary wave from the surface due to higher mean ozone in the stratosphere (Figure 3), which creates larger contrast of solar heating in the longitudinal direction of planetary wave and produces stronger wave-mean flow interaction in the

310 stratosphere in HS years. This should be examined in more detail in a future study. See Kuroda et al. [2007] for such analysis in the SH.

In this paper, we considered ozone as a memory of the winter-NAO to the following summer. In contrast, Ogi et al. [2003] considered surface condition such as snow, sea ice and SST as a memory. To investigate the role of ozone and surface condition on the memory of the winter-NAO to the following summer, controlled numerical experiment will be needed in a future study.

Two large volcanic eruptions (El Chichon and Pinatubo) took place in HS years during our period of analysis. To examine the effect of volcanic eruption on the result, 
we performed the same calculation after removing the years following the volcanic eruptions. The results demonstrate that the effect was very small (not shown).

We did not consider effects of QBO, ENSO in the present analysis. However,

325 previous analysis indicates that solar influence on climate is much affected by these phenomena [e.g., Labitzke and van Loon, 1999]. Although our present analysis is statistically too short to examine such an effect, analysis of 43-years of data from 1958 to 2000 shows that solar cycle modulation of the NAO is more prominent in the westerly phase of 50-hPa QBO wind. See Kuroda [2007b] for more detail.

\section{Acknowledgments}

335 The authors are grateful to W. J. Randel for providing ozone data. Solar radio flux data were obtained from the NOAA National Geophysical Data Center. This work was supported in part by a Grant-in-Aid (16340144, 18204043, 19340135) for Science 
Research of the Ministry of Education, Culture, Sports, Science, and Technology of Japan. 


\section{Appendix A}

The model used in this study is the zonal-mean quasi-geostrophic model on a sphere that was used in Plumb [1982], Haynes and Shepherd [1989], and Kuroda [2005]:

345

$$
\begin{aligned}
& \frac{\partial u}{\partial t}-2 \Omega v \sin \phi=F+G \\
& 2 \Omega u \sin \phi=-\frac{1}{a} \frac{\partial \Phi}{\partial \phi} \\
& \frac{\partial \Phi}{\partial p}=-\frac{R T}{p} \\
& \frac{\partial T}{\partial t}-\Gamma \omega=Q+S \\
& \frac{1}{a \cos \phi} \frac{\partial}{\partial \phi}(v \cos \phi)+\frac{\partial \omega}{\partial p}=0
\end{aligned}
$$

350 where

$$
\begin{aligned}
& F=-\frac{1}{a \cos ^{2} \phi} \frac{\partial}{\partial \phi}\left[\overline{u^{\prime} v^{\prime}} \cos ^{2} \phi\right] \\
& Q=-\frac{1}{a \cos \phi} \frac{\partial}{\partial \phi}\left[\overline{v^{\prime} T^{\prime}} \cos \phi\right]
\end{aligned}
$$

are eddy mechanical and thermal forcings, $G$ and $S$ are frictional forcing and diabatic

355 heating, $\phi$ is the latitude, $\omega$ is the vertical pressure velocity, $\Gamma=-\partial T_{0} / \partial p+\kappa T_{0} / p$ is the stability of the basic atmosphere, $\Omega$ is the angular velocity of the Earth, $a$ is the radius of the Earth, field variables with primes denote departure from zonal mean, 
overbar denotes zonal averaging, and other symbols follow the usual convention [for example, see Andrews et al., 1987].

Boundary conditions of the equation should be

$$
\frac{D \Phi}{D t}=0
$$

for the lower boundary and $\omega=0$ for the upper boundary, and lateral conditions are $v=0$ at $\phi= \pm \pi / 2$, where $D / D t$ is a material derivative.

As Equations (A.1) can be put into an elliptical differential equation of $\omega$

$$
\begin{aligned}
& \frac{1}{\cos \phi} \frac{\partial}{\partial \phi}\left(\frac{\cos \phi}{\sin ^{2} \phi} \frac{\partial \omega}{\partial \phi}\right)+\frac{4 \Omega^{2} a^{2} p}{R \Gamma} \frac{\partial^{2} \omega}{\partial p^{2}} \\
& =\frac{2 \Omega a p}{R \Gamma \cos \phi} \frac{\partial}{\partial \phi}\left[\frac{\cos \phi}{\sin \phi} \frac{\partial}{\partial p}(F+G)\right]-\frac{1}{\Gamma \cos \phi} \frac{\partial}{\partial \phi}\left[\frac{\cos \phi}{\sin ^{2} \phi} \frac{\partial}{\partial \phi}(Q+S)\right]
\end{aligned}
$$

the meridional circulation can be calculated from this and a continuum equation (the last

370 equation of (A.1)) with boundary conditions. The surface pressure change is then obtained from $\omega$ on the lower boundary.

For practical method to solve these equations, see Appendix of Kuroda and Kodera (2004). 


\section{References}

380 Andrews D.G., J.R. Holton, and C.B. Leovy (1987), Middle atmosphere dynamics, Academic Press, 489 pp.

Fioletov, V. E. and T. G. Shepherd (2003), Seasonal persistence of midlatitude total ozone anomalies, Geophys. Res. Lett., 30, 1417, doi:10.1029/2002GL016739.

Frith, S. M., R. S. Stolarski (2005), Merged profile ozone data from the SBUV/SBUV2 series of instruments, Eos Trans. AGU, 86(52), Fall Meet. Suppl., Abstract A23B0943

Haynes, P.H. and T.G. Shepherd (1989), The importance of surface pressure change in the response of the atmosphere to zonally-symmetric thermal and mechanical forcing, Quart. J Roy. Meteorol. Soc. 115, 1181-1208.

390 Hood, L.L., J.L. Jikikowic, and J.P. McCormack (1993), Quasi-decadal variability of the stratosphere: Influence of long-term solar ultraviolet variations, J. Atmos. Sci., 50, 3941-3958.

Haigh, J. D. (2003), The effect of solar variability on the Earth's climate, Phil, Trans. Roy. Soc. A, 95-111, doi:10.1098/rsta.2002.1111.

395 Hurrell, J. W. (1996), Influence of variations in extratropical wintertime teleconnections on northern hemisphere temperature, Geophys. Res. Lett., 23, 665-668. 
Kodera, K. (2002), Solar cycle modulation of the North Atlantic Oscillation: Implication in the spatial structure of the NAO, Geophys. Res. Lett., 29(8), 1281, doi:10.1029/2001GL014557.

400 Kodera, K. (2003), Solar influence on the spatial structure of the NAO during the winter 1900-1999, Geophys. Res. Lett., 30(4), 1175, doi:10.1029/2002GL016584.

Kodera, K., and Y. Kuroda (2002), Dynamical response to the solar cycle, J. Geophys. Res.,107(D24), 4749, doi:10.1029/2002JD002224.

Kuroda, Y. (2005), On the influence of the meridional circulation and surface pressure 405 change on the Arctic Oscillation, J. Geophys. Res.,110, D21107, doi:10.1029/2004JD005743.

Kuroda, Y. (2007a), Correction to "On the influence of the meridional circulation and surface pressure change on the Arctic Oscillation”, J. Geophys. Res., doi:10.1029/2007JD008569.

410 Kuroda, Y. (2007b), Effect of QBO and ENSO on the solar cycle modulation of winter north Atlantic Oscillation, J. Meteorol. Soc. Japan, in press.

Kuroda, Y. and K. Kodera (2001), Variability of the polar-night jet in the northern and southern hemispheres, J. Geophys. Res., 106, 20,703-20,713. 
Kuroda, Y. and K. Kodera (2002), Effect of solar activity on the Polar-night Jet 415 Oscillation in the northern and southern hemisphere winter, J. Meteorol. Soc. Jpn, 80, 973-984.

Kuroda, Y. and K. Kodera (2004), Role of the polar-night jet oscillation on the formation of the Arctic Oscillation in the northern hemisphere winter, J. Geophys. Res.,109, D11112, doi:10.1029/2003JD004123.

420 Kuroda, Y., and K. Kodera (2005), Solar cycle modulation of the southern annular mode, Geophys. Res. Lett., 32, L13802, doi:10.1029/2005GL022516.

Kuroda, Y., and K. Shibata (2006), Simulation of solar-cycle modulation of the southern annular mode using a chemistry-climate model, Geophys. Res. Lett., 33, L05703, doi:10.1029/2005GL025095.

425 Kuroda, Y., M. Deushi, and K. Shibata (2007), Role of solar activity in the tropospherestratosphere coupling in the southern hemisphere winter, Geophys. Res. Lett., 34, L21704, doi:10.1029/2007GL030983.

Labitzke K. G, and H. van Loon (1999), The stratosphere -Phenomena, History, and Relevance-, 179 pp, Springer, New York.

430 Lean, J.L. et al. (1997), Detection and parametarization of variations in solar mid- and near-ultraviolet radiation (200-400 nm), J. Geophys. Res., 102, 29,939-29,956. 
Lean, J.L., O.R. White, W.C. Livingston, and J.M. Picone (2001), Variability of a composite chromosphere irradiance index during the 11-year activity cycle and over longer time periods, J. Geophys. Res., 106, 10,645-10,658.

435 McCormack, J.P., and L.L. Hood (1996), Apparent solar cycle variations of upper stratospheric ozone and temperature: Latitude and seasonal dependences, J. Geophys. Res., 101, 20,933-20,944.

Ogi, M., K. Yamazaki, and Y. Tachibana (2003), Solar cycle modulation of the seasonal linkage of the North Atlantic Oscillation (NAO), Geophys. Res. Lett., 30(22), 2170, doi:10.1029/2003GL018545.

Ogi, M., K. Yamazaki, and Y. Tachibana (2004), The summertime annular mode in the northern hemisphere and its linkage to the winter mode, J. Geophys. Res., 109, D20114, doi:10.1029/2004JD004514.

Pap, J. M., and P. Fox (2004), Solar variability and its effects on climate, American Geophysical Union, 366 pp.

Plumb, R.A. (1982), Zonally symmetric Hough modes and meridional circulations in the middle atmosphere, J. Atmos. Sci. 39, 983-991.

Randel, W. J., and F. Wu (2007), A stratospheric ozone profile data set for 1979-2005: variability, trends, and comparisons with column ozone data, J. Geophys. Res., 112, 450 D06313, doi:10.1029/2006JD007339. 
Rottman, G.J. (1988), Observations of solar UV and EUV variability, Adv. Space Res., 8, (7)53-(7)66.

Shibata, K., M. Deushi, T. T. Sekiyama, and H. Yoshimura (2005), Development of an MRI chemical transport model for the study of stratospheric chemistry, Pap. Meteor.

Soukharev, B. E. and L. L. Hood (2006), Solar cycle variation of stratospheric ozone: Multiple regression analysis of long-term satellite data sets and comparison with models, J. Geophys. Res., 111, D20314, doi:10.1029/2006JD007107.

Thompson, D.W.J. and J.M. Wallace (1998), The Arctic oscillation signature in the 460 wintertime geopotential height and temperature fields, Geophys. Res. Lett. 25, 12971300.

Uppala, S. M. et al., The ERA-40 Reanalysis (2005), Q. J. Roy. Meteor. Soc., 131, 2961-3012, doi:20.125/qj.04.176.

Wang, H. J., D. M. Cunnold, L. W. Thomason, J. M. Zawodny, and G. E. Bodeker 465 (2002), Assessment of SAGE version 6.1 ozone data quality, J. Geophys. Res., 107(D23), 4691, doi:10.1029/2002JD002418. 
Y. Kuroda and K. Shibata, Meteorological Research Institute, Tsukuba, 305-0052, Japan. (kuroda@mri-jma.go.jp, kshibata@mri-jma.go.jp)

K. Yamazaki, Faculty of Environmental Earth Science, Hokkaido University, Sapporo, 060-0810, Japan. (yamazaki@ees.hokudai.ac.jp) 


\section{Figure captions}

Figure 1, Time coefficients of winter-mean NAO index (upper panels) and standardized F10.7 index (lower panels) used in the present study. Closed (open) circle in the lower panels indicate High (Low) Solar year. Year corresponds to the months of January.

480

Figure 2, Climatological zonal-mean zonal wind for the HS years (upper panels), LS years (middle panels), and their differences (lower panels). The contour interval is 10 $\mathrm{m} / \mathrm{s}$ in the upper and middle panels and $2 \mathrm{~m} / \mathrm{s}$ in the lower panels. Shading in the upper and middle panels indicates the standard deviation (light shading $1 \mathrm{~m} / \mathrm{s}$, middle

485 shading $2 \mathrm{~m} / \mathrm{s}$, and heavy shading $5 \mathrm{~m} / \mathrm{s}$ ). Shading in the lower panels indicates the area of 95\% significance levels.

Figure 3, Same as Figure 2, except showing ozone density. The contour interval is 1 ppmv in the upper and middle panels and 0.05 ppmv in the lower panels. In the upper 490 and middle panels, light shading indicates 0.05 ppmv, middle shading $0.1 \mathrm{ppmv}$, and heavy shading 0.2 ppmv. 
Figure 4, Lagged correlation coefficients between December-February mean NAO index and the two-month mean zonal-mean zonal wind at each grid point for the 495 period of 1978-2000 for all years (upper panels), HS years (middle panels), and LS years (lower panels). The contour interval is 0.1 and contours are drawn for absolute values greater than or equal to 0.6 and for zero. Shading is applied to regions where the absolute value of the correlation is greater than 0.5. Dashed lines indicate negative values.

Figure 5, Same as Figure 4, except showing the E-P flux and its divergence $\left(1^{\text {st }}\right.$ and $3^{\text {rd }}$ rows), and residual velocity and ozone density ( $2^{\text {nd }}$ and $4^{\text {th }}$ rows) for December to April for HS years (upper panels) and LS years (lower panels). Correlations of the EP flux and residual velocity are shown by arrows. Only arrows whose absolute value of correlations is greater than 0.6 are plotted.

Figure 6, Same as Figure 4, except showing the lagged regression of the E-P flux (arrow) and zonal-mean zonal wind ( $1^{\text {st }}$ row), temperature $\left(2^{\text {nd }}\right.$ row $)$, ozone density ( $3^{\text {rd }}$ row), and solar heating ( $4^{\text {th }}$ row) from May to August for HS years. Contour 
510 intervals of the zonal wind, temperature, ozone density, and solar heating are $0.5 \mathrm{~m} / \mathrm{s}$, $0.2 \mathrm{~K}, 0.02 \mathrm{ppmv}$, and $0.005 \mathrm{~K} / \mathrm{day}$, respectively. Shading is applied to regions where the absolute value of correlation is greater than 0.5. Only E-P fluxes for which the absolute value of correlations is greater than 0.5 are plotted. They are scaled by the reciprocal square root of the pressure.

Figure 7, Lagged regression coefficients between December-February mean NAO index and the monthly mean temperature at 50-hPa (upper panels) and 1000-hPa (lower panels) from June to August for HS years. Contour intervals of 50- and 1000-hPa temperature are $0.2 \mathrm{~K}$ and $0.5 \mathrm{~K}$, respectively.

Figure 8, Zonal-mean of the regressed SLP (upper panels) and the potential surface pressure change (PPC, dPs/dt) due to Eulerian wave forcings (lower panels). Quantities for June to August associated with winter-mean NAO index in HS years (upper panels) and the Summer-AO (lower panels) are shown. Red lines in $2^{\text {nd }}$ and

$5254^{\text {th }}$ rows indicate values due solely to mechanical forcing at 500-hPa and above. The unit of vertical axis is $1 \mathrm{hPa}(\mathrm{hPa} /$ day) for the SLP (PPC). 
Figure 9, Same as Figure 4, except showing the lagged regression of the Eulerian meridional circulation (arrow) and Eulerian mechanical forcing (contour) (upper 530 panels), and residual velocity (arrow) and zonal-mean temperature (contour) (lower panels) from first to last 10-day of June. Contour intervals of the Eulerian mechanical forcing (zonal-mean temperature) is $0.2 \mathrm{~m} / \mathrm{s} /$ day $(0.2 \mathrm{~K})$. Only arrows with a larger correlation (greater than 0.5) are shown.

535 Figure 10, Line plots showing climatological temperature difference between 200-hPa and $300-\mathrm{hPa}$ at $60^{\circ} \mathrm{N}$ (with open circles) and $60^{\circ} \mathrm{S}$ (with closed circles).

Figure 11, Same as Figure 6, except showing the lagged regression of ozone density $\left(1^{\text {st }}\right.$ 540 row), and solar heating ( $2^{\text {nd }}$ row) from May to August for HS years of combined $\operatorname{SBUV}(/ 2)$ and SAGE II data. 


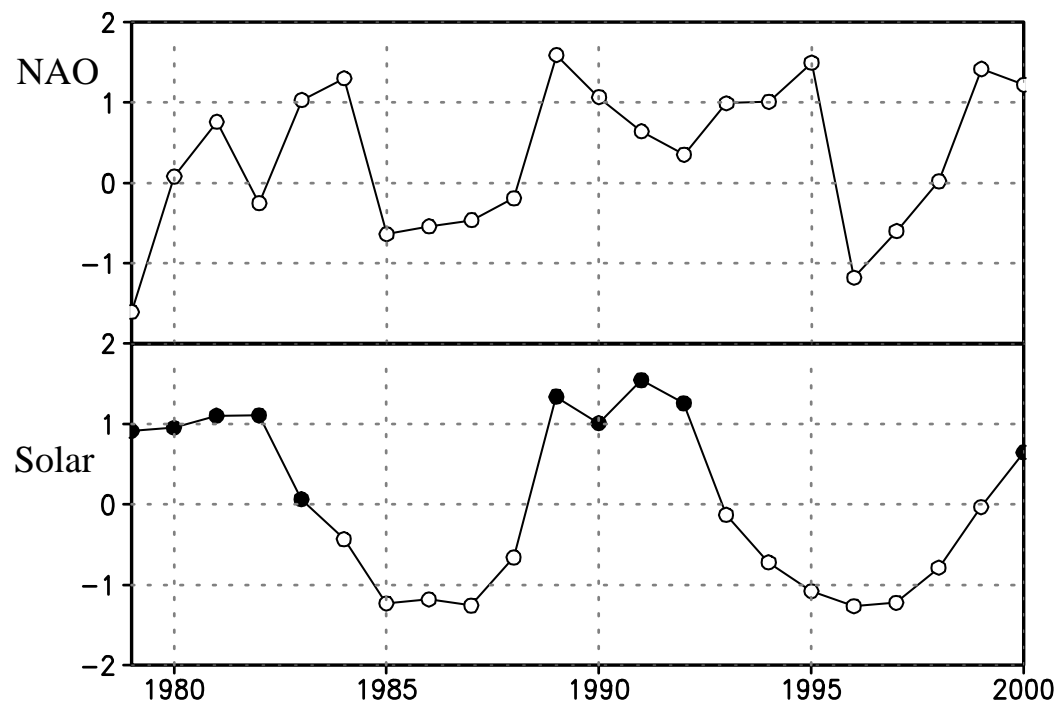

550

Figure 1
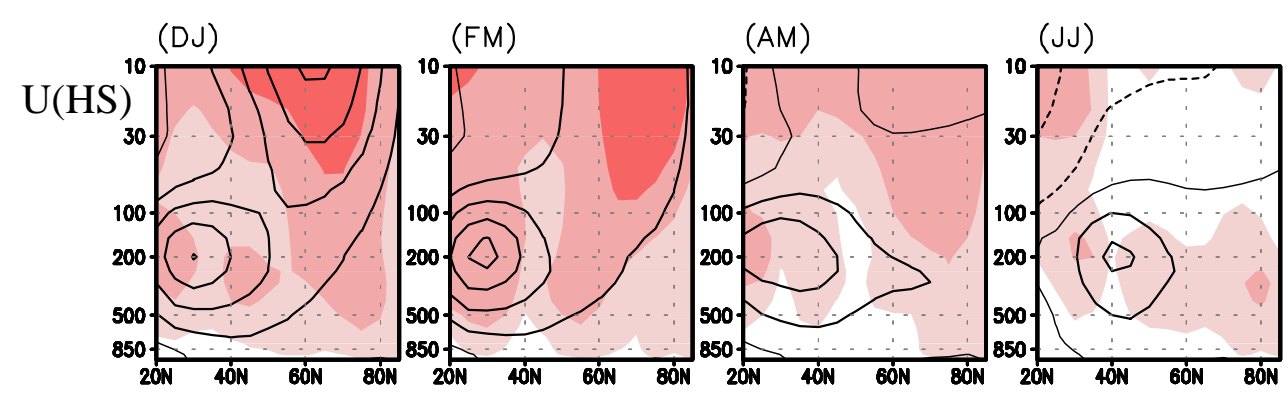

555
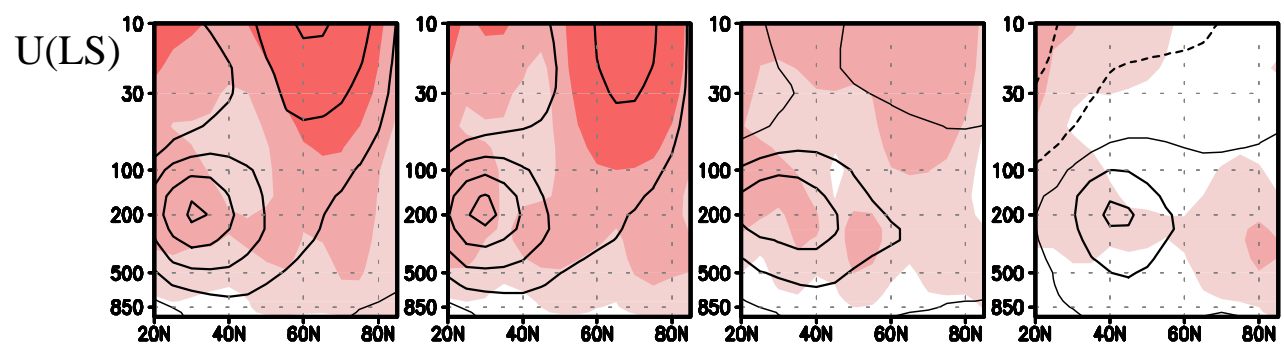

U(HS-LS)

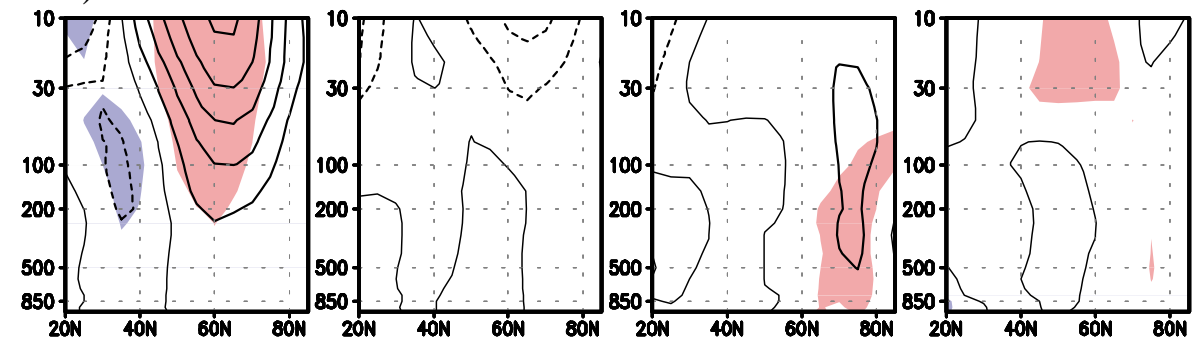

Figure 2 

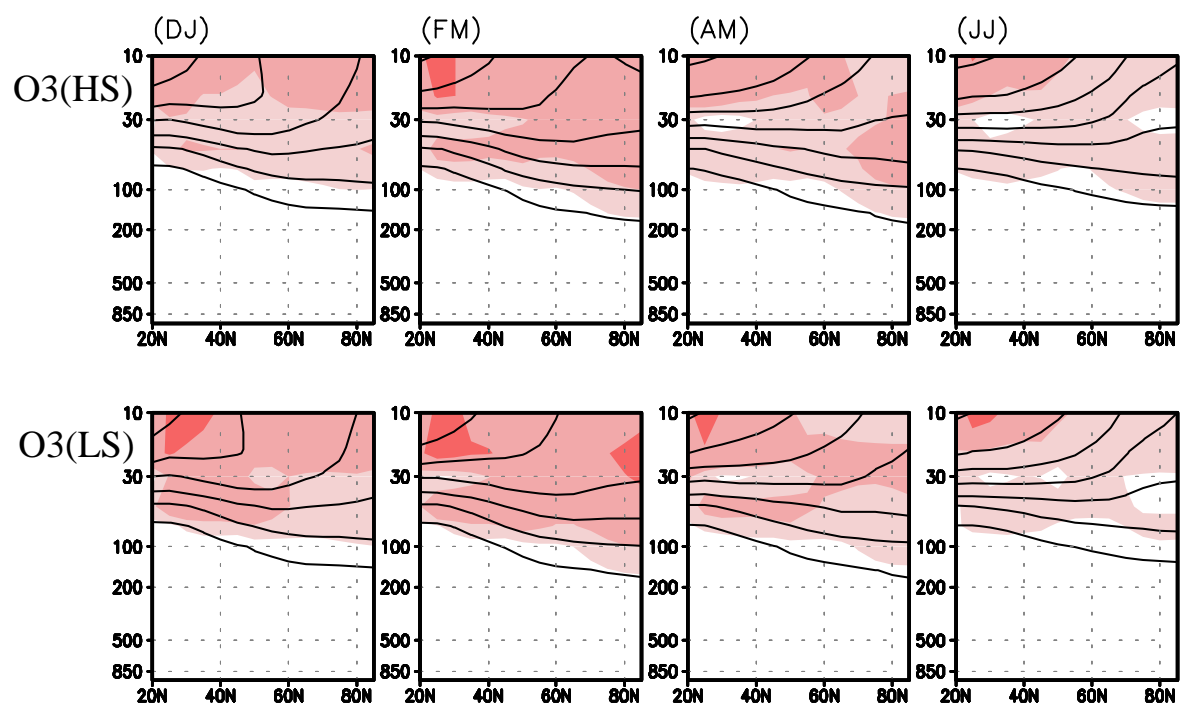

O3(HS-LS)

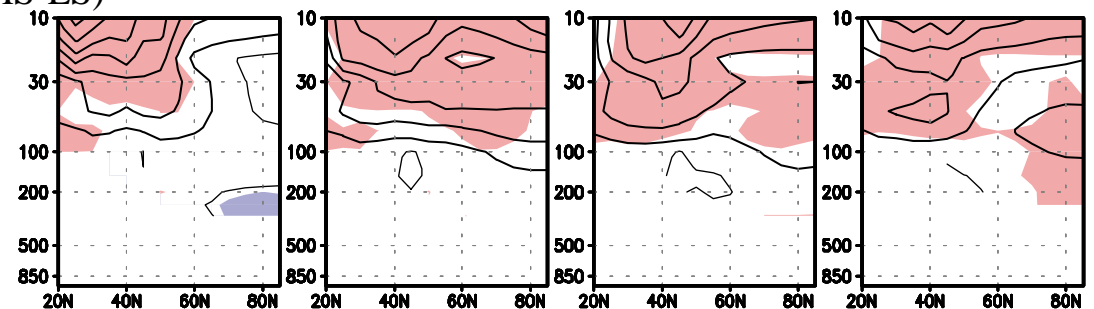

Figure 3

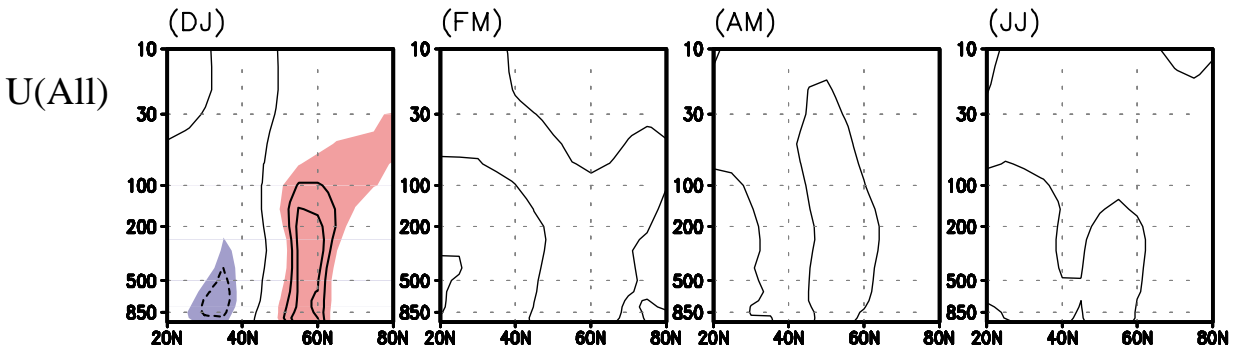

$\mathrm{U}(\mathrm{HS})$

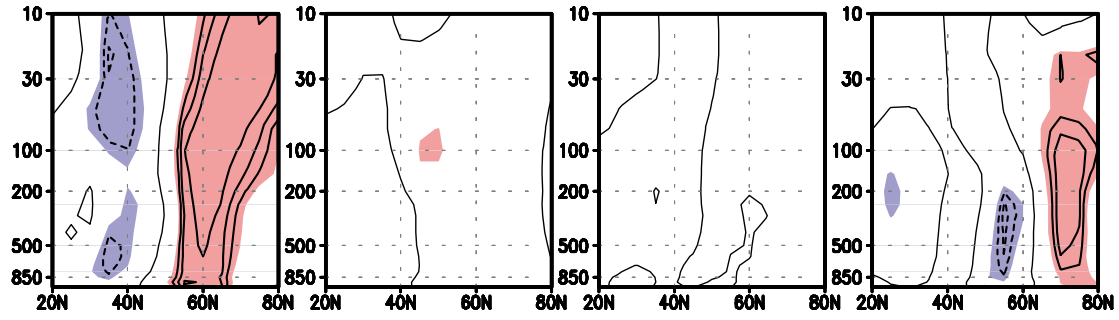

U(LS)

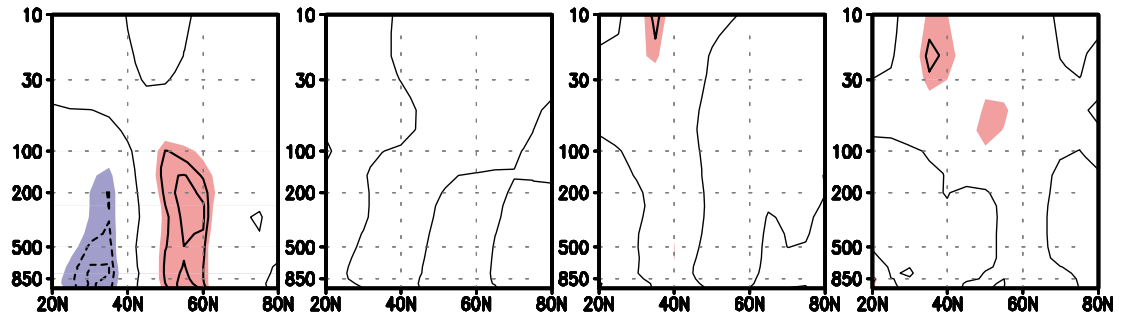

Figure 4 

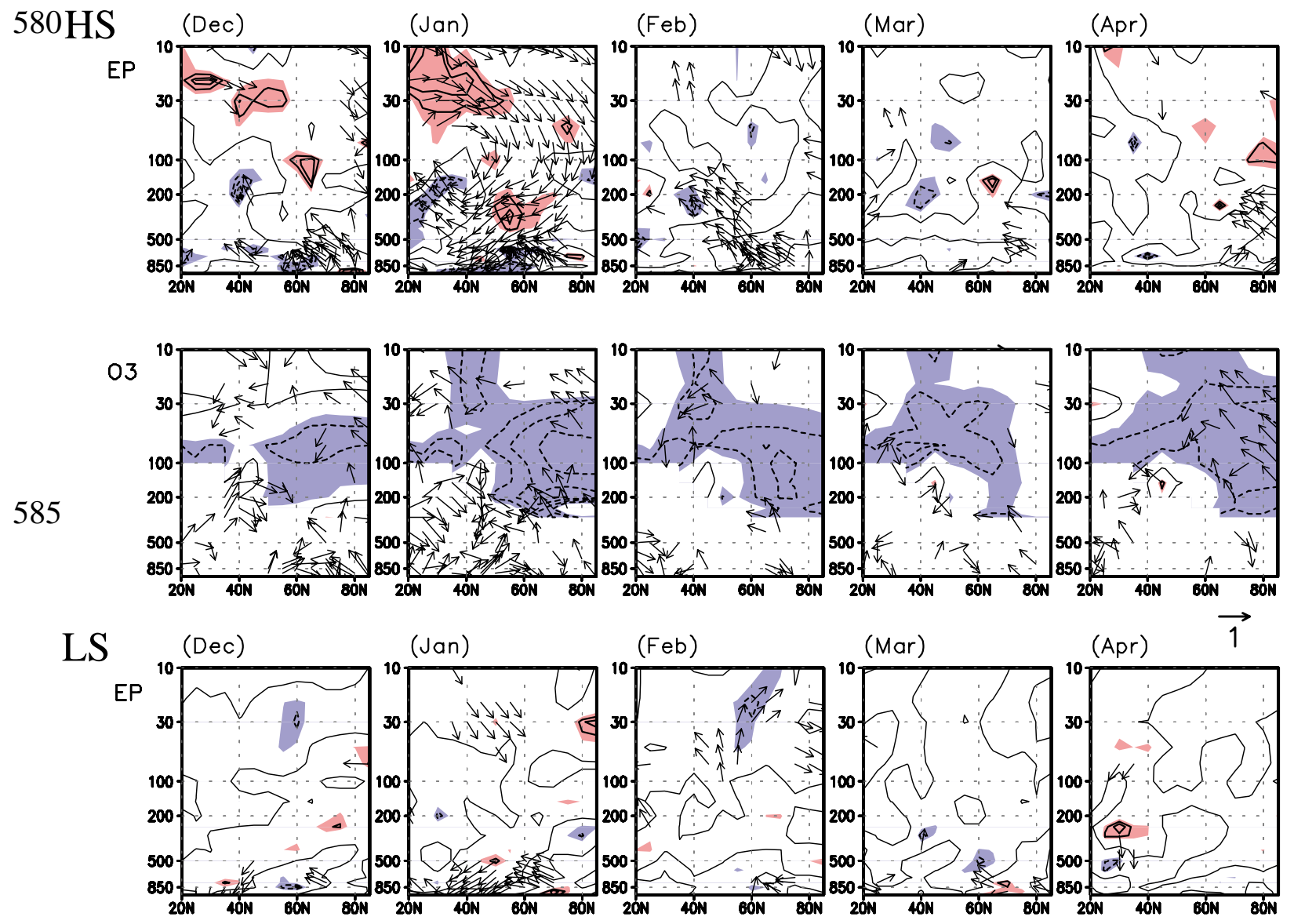

590

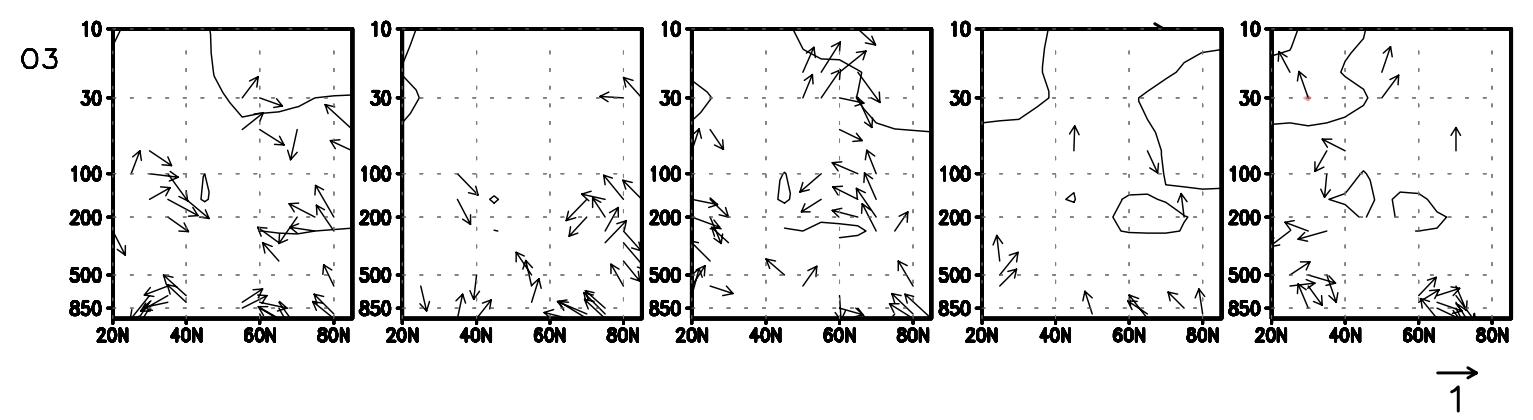

Figure 5 
U
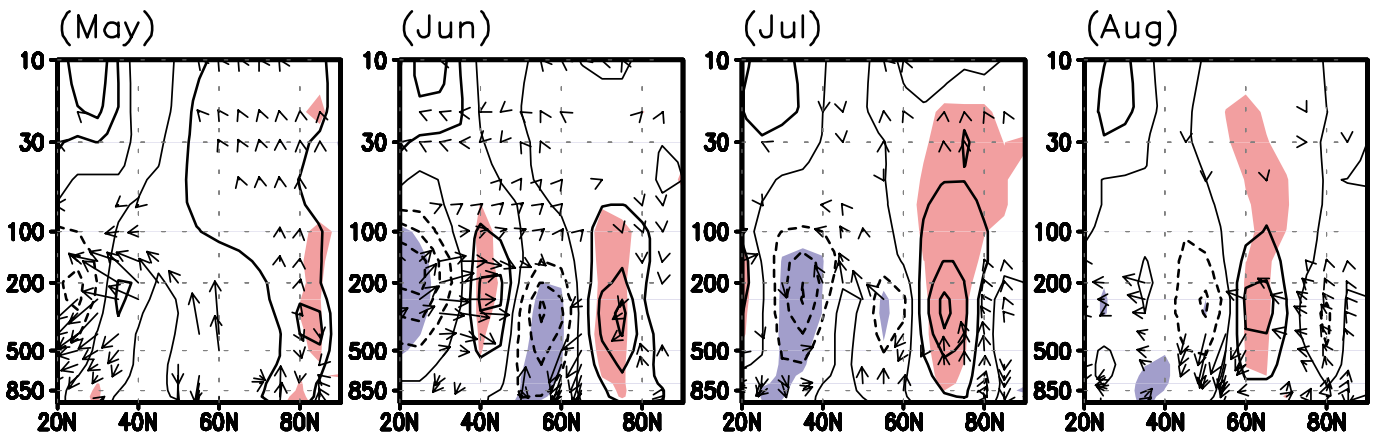

$$
\mathrm{T}
$$
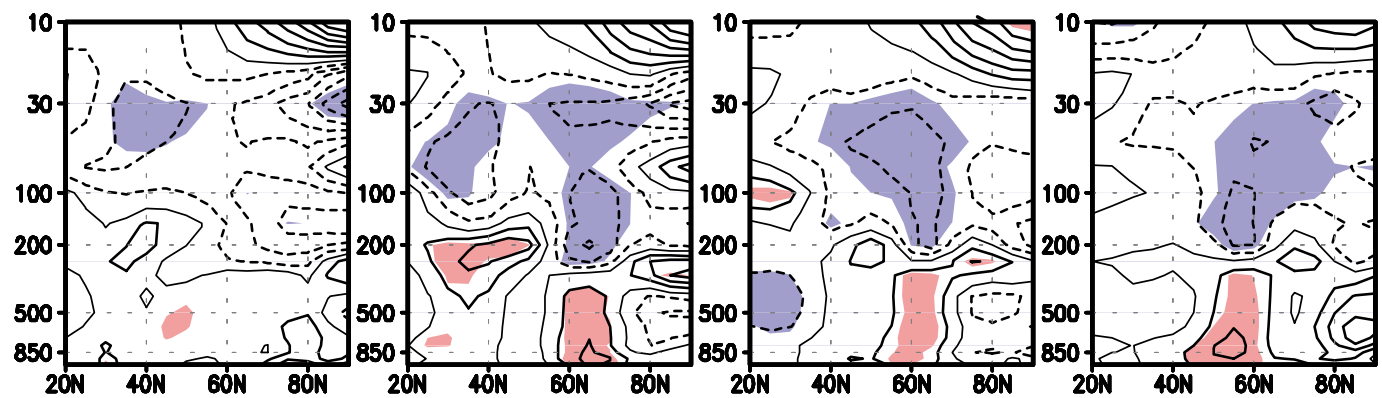

605
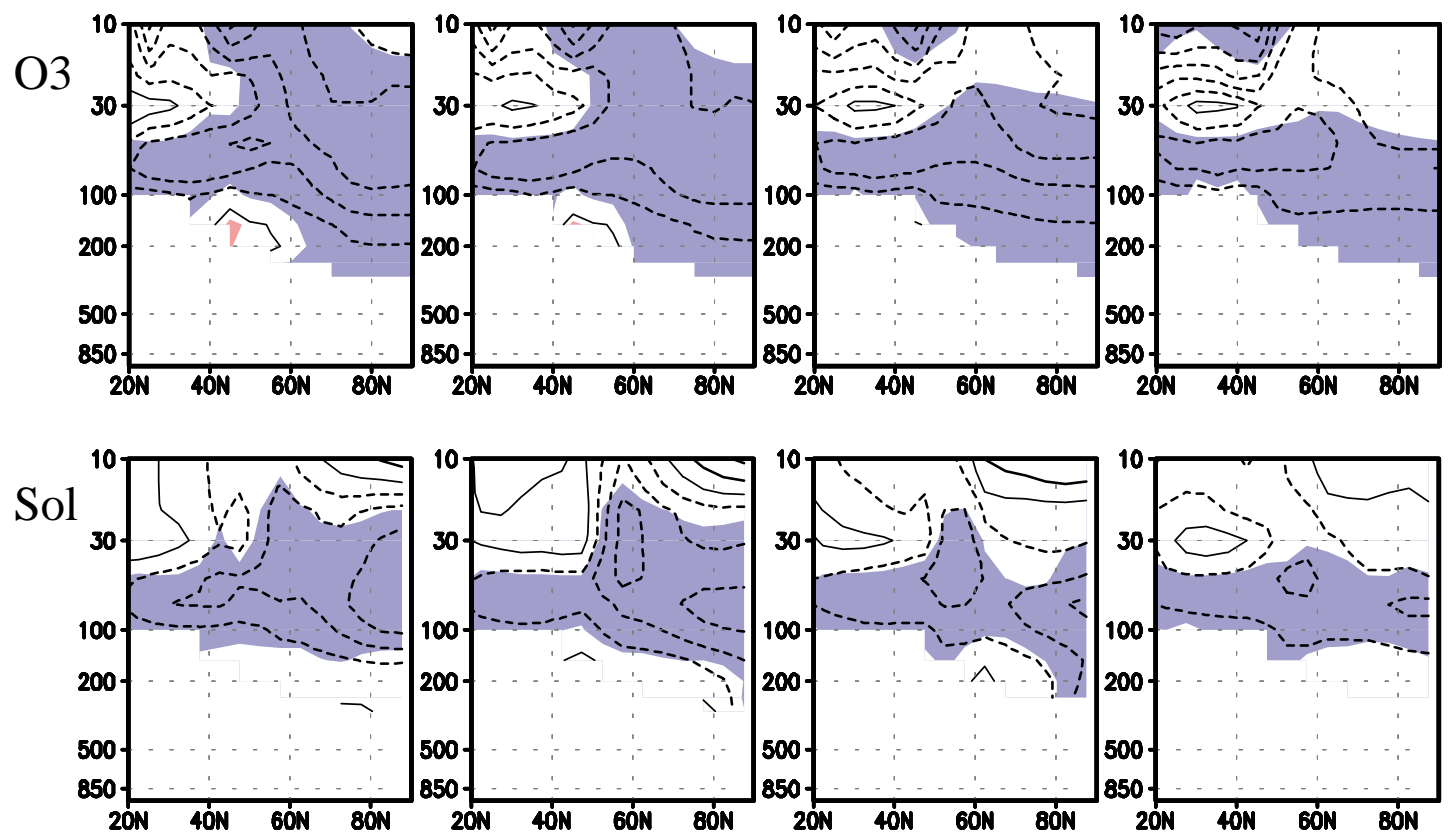

Figure 6 

(Jun)
(Jul)
(Aug)

T50
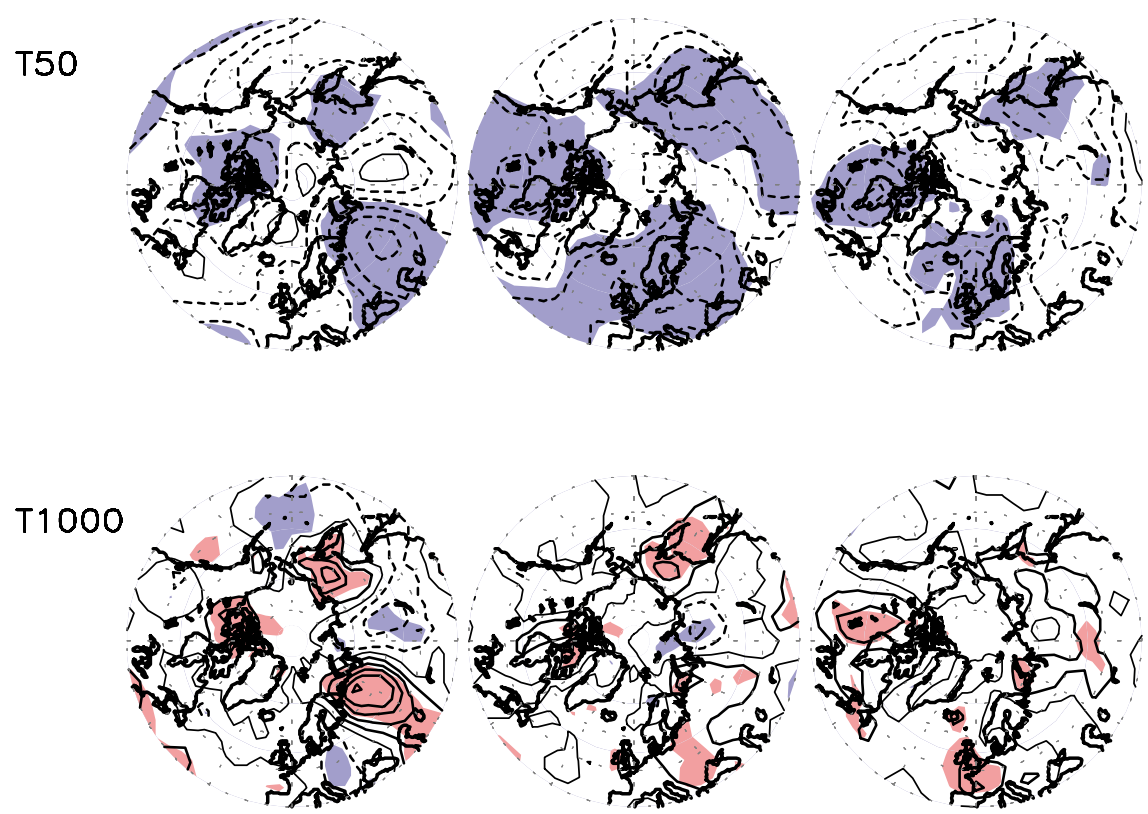

Figure 7

625

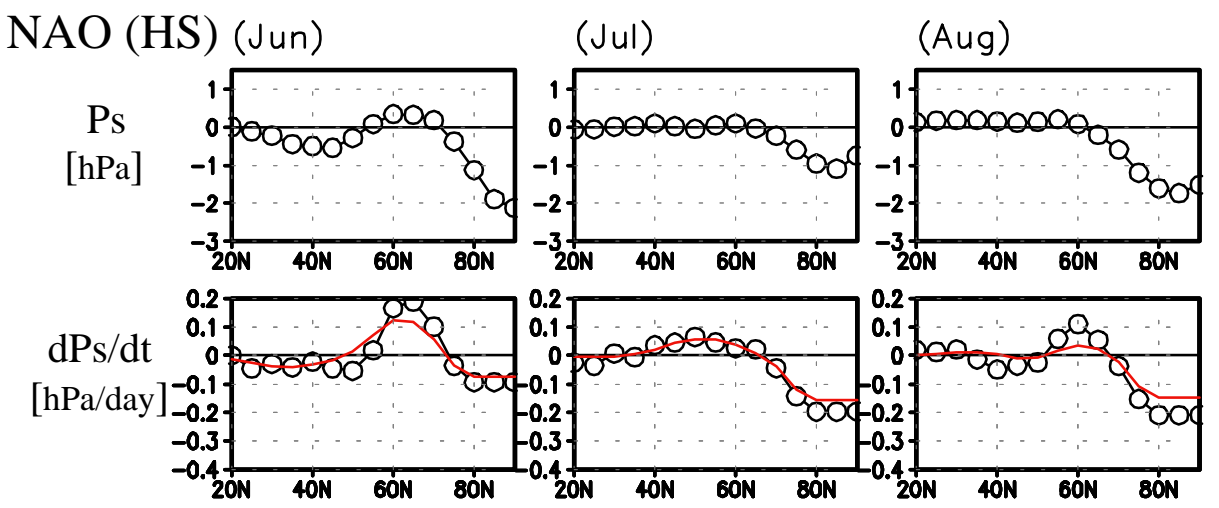

630

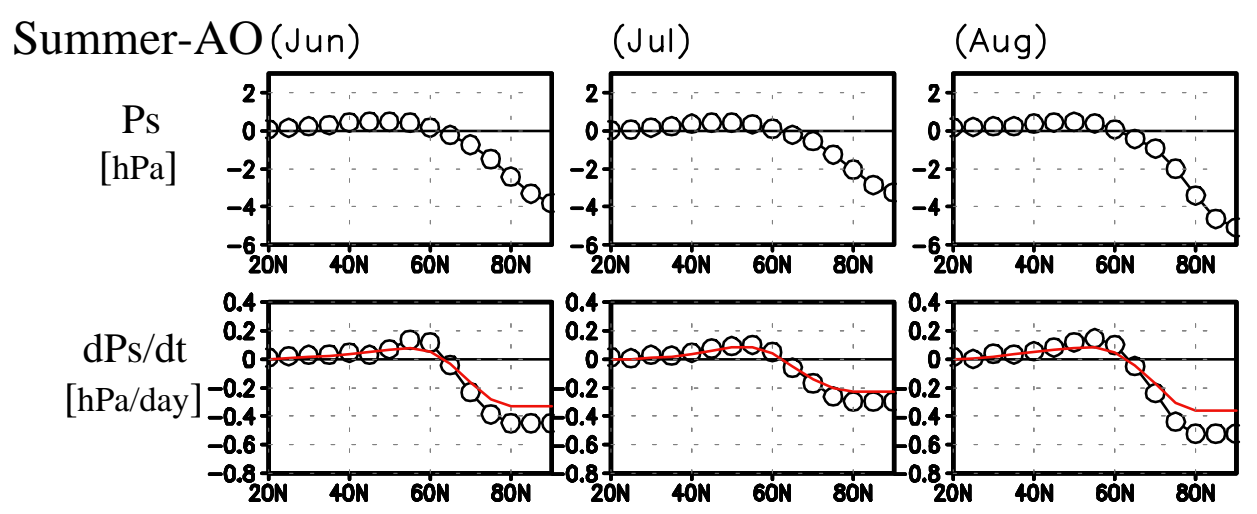

Figure 8 
635
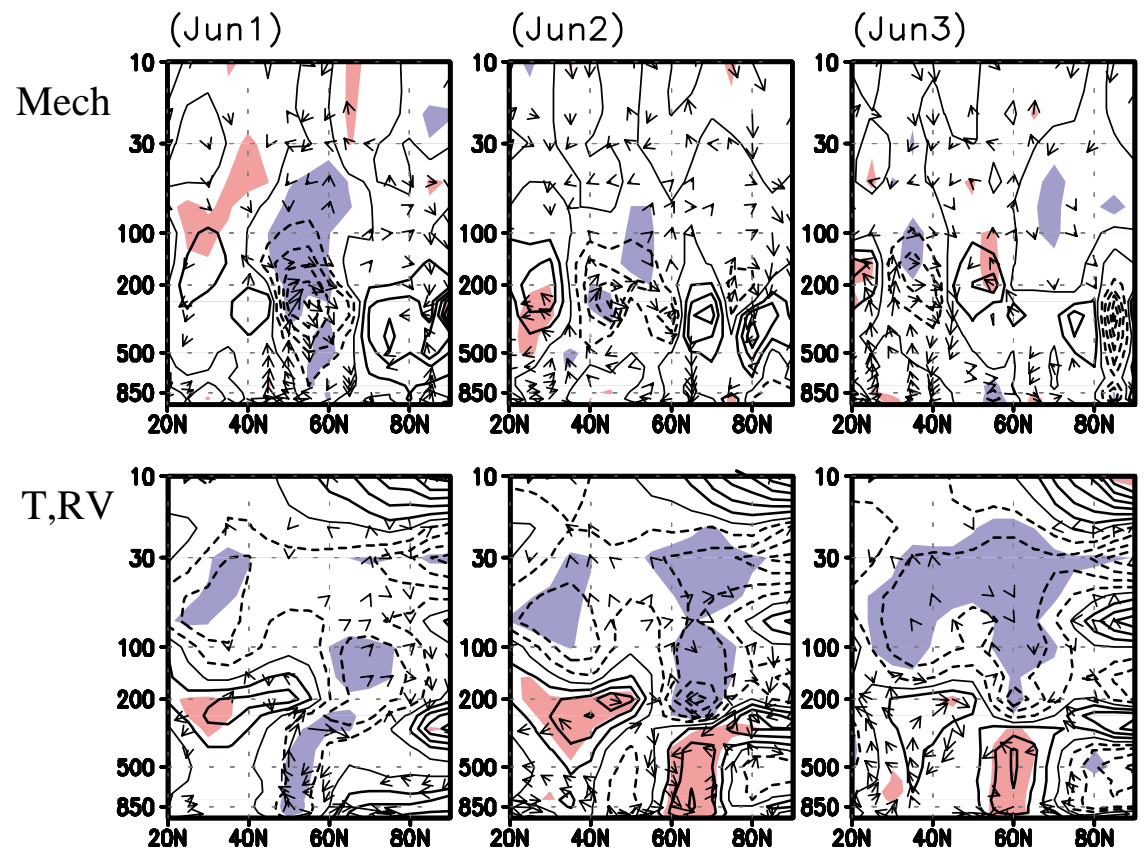

Figure 9

645

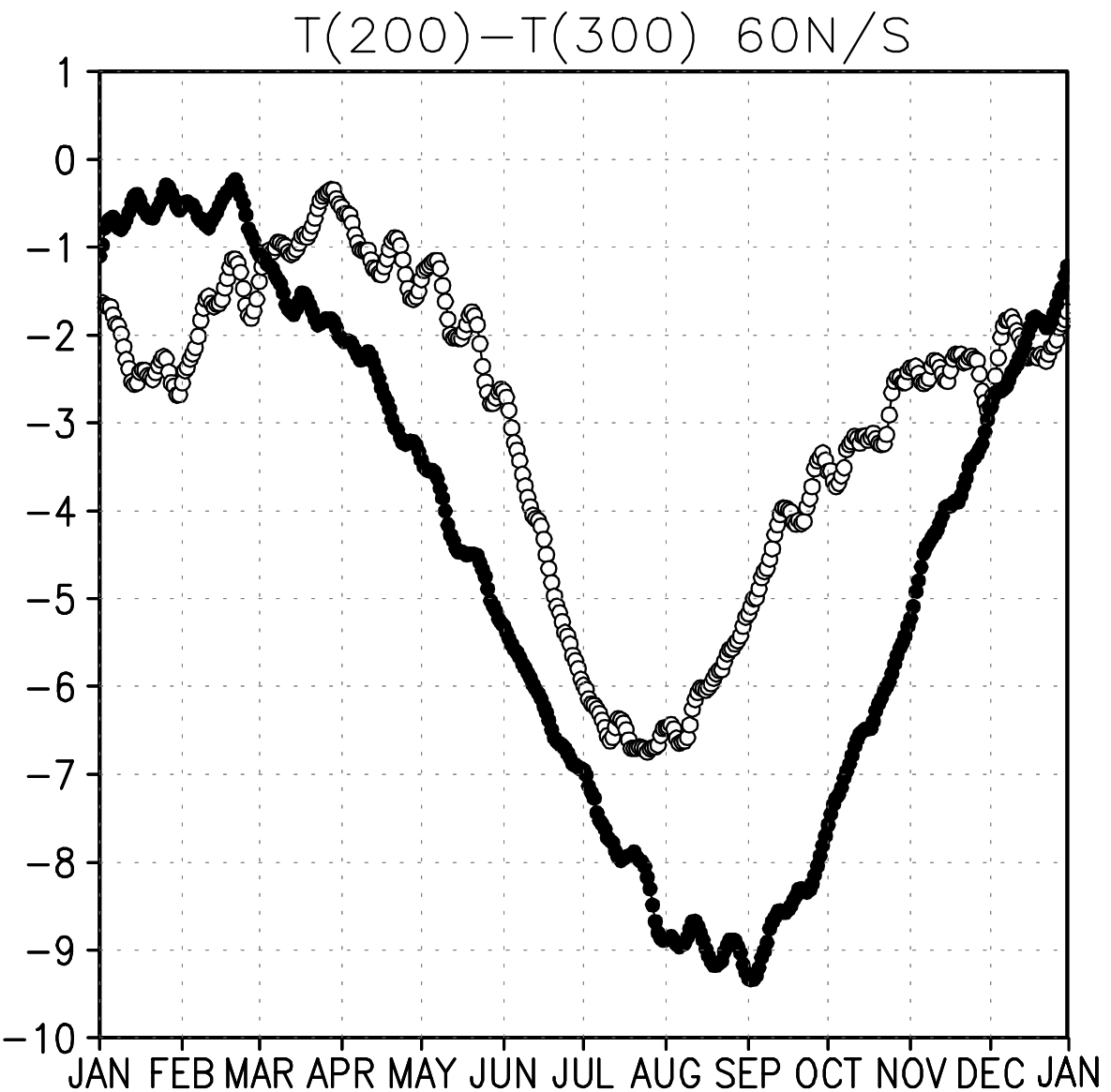

Figure 10 

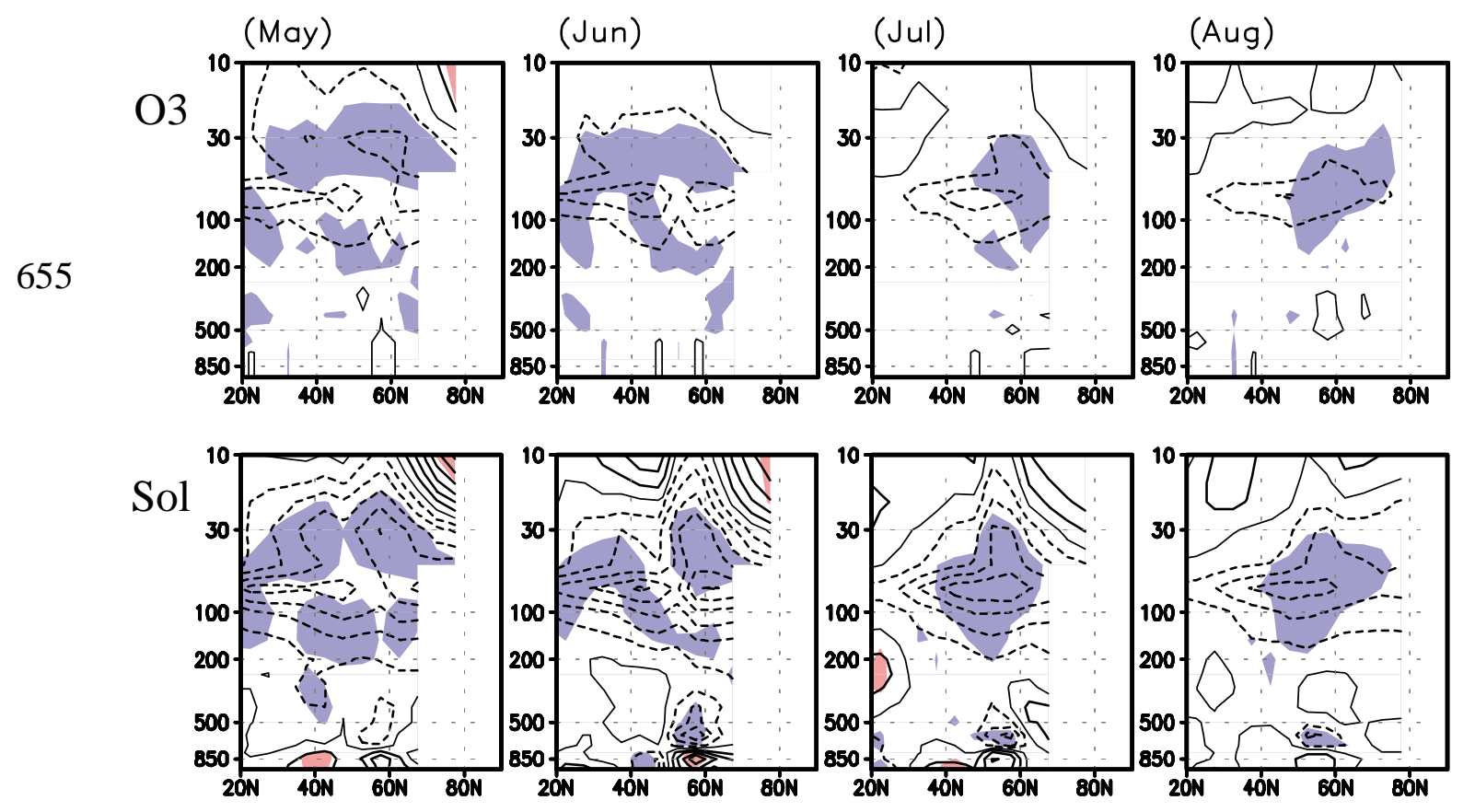

Figure 11 